\title{
The teaching of medical ethics
}

\author{
K J Dennis and M R P Hall Faculty of Medicine, University of Southampton
}

\section{At Southampton University Medical School}

\begin{abstract}
For centuries medical schools in Britain and elsewhere had a fairly static curriculum based on what might be called the 'three Rs' of medicine, and consequently had to make room for new subjects as the need arose in a fashion which was sometimes makeshift. However, Southampton University has only had a medical school for six years, and therefore their course on medical ethics and legal medicine was carefully integrated into the curriculum after some preliminary experiments carried out by a subcommittee which is continually reviewing the situation. Medical ethics has now a definite place in the fourth year, preceded by an introduction to ethical problems encountered in medicine in the first year. Not only do members of the medical faculty participate in this teaching but also members of the faculties of law and the arts.
\end{abstract}

Various aspects of philosophy and teaching at the Southampton University Medical School have already been described 1-7. One of the major problems facing any medical school is not only how it should teach its students but what subjects should be included in the medical curriculum. Forensic medicine and toxicology are traditional subjects but times change and nearly all their content can be taught better within the confines of pathology and pharmacology. Consequently, with the need to introduce new subiects and rationalize the curriculum, forensic medicine was omitted from the initial programme. Nevertheless this would have meant that important aspects of legal medicine would no be taught to medical students. Another drawback might have been that ethical problems would receive little consideration, other than when they cropped up in the course of routine teaching, for example, abortion in obstetrics and gynaecology and terminal care in geriatric medicine.

Such an omission is important not only because the qualified doctor needs to know something about the legal aspects of medicine and the medical moral code but also because the student himself during his training will meet difficult and awkward situations. If he does not know, for example, how to react to questions from patients with cancer, then that lack of knowledge may create emotional pressures which may become excessive when superimposed on top of the other pressures which are a natural part of the medical student's lot. Time, therefore, had to be found for the inclusion of medical ethics and legal medicine in the teaching programme within the medical curriculum.

\section{Reviewing the medical curriculum}

The medical curriculum and its teaching is continually under review by the Faculty of Medicine through its curriculum subcommittee, and modifications have been made on an ongoing basis so that the form of the curriculum is at present as shown in the table.

In 1972 one of us (KJD) was asked by the curriculum subcommittee to convene a small group to make recommendations concerning the teaching of medical ethics and legal medicine in the third year. This working group consisted initially of people whose primary interest lay in the fields of human reproduction, forensic pathology, geriatric medicine, neurosurgery, child health and primary medical care. The membership of the group, however, fluctuated, some members being unable to attend all meetings, and others being added to it. These included a professor from the Faculty of Law, a consultant radiotherapist and a general practitioner with considerable experience of the British Medical Association and its function.

It was agreed that some topics should be incorporated in a specific course, that others should be taught within the content of other courses, and the practical aspects, such as certification, would be taught in the preregistration year. It was realized that this third decision would mean organizing a number of lectures or discussions on a local hospital basis throughout Wessex and that some graduates might have no formal teaching if they took jobs outside Wessex.

Topics for inclusion in the specific course included the ethics of research in its widest sense, medical records and confidentiality, functions of the General Medical Council and other medical bodies, the doctor and the law, sudden death and the coroner's system, medical causes for suspicion and criminal investigation, medico-legal aspects of offences against women and children and the medico-legal aspects of poisoning. 
Table Plan of the medical curiculum leading to final $B M$

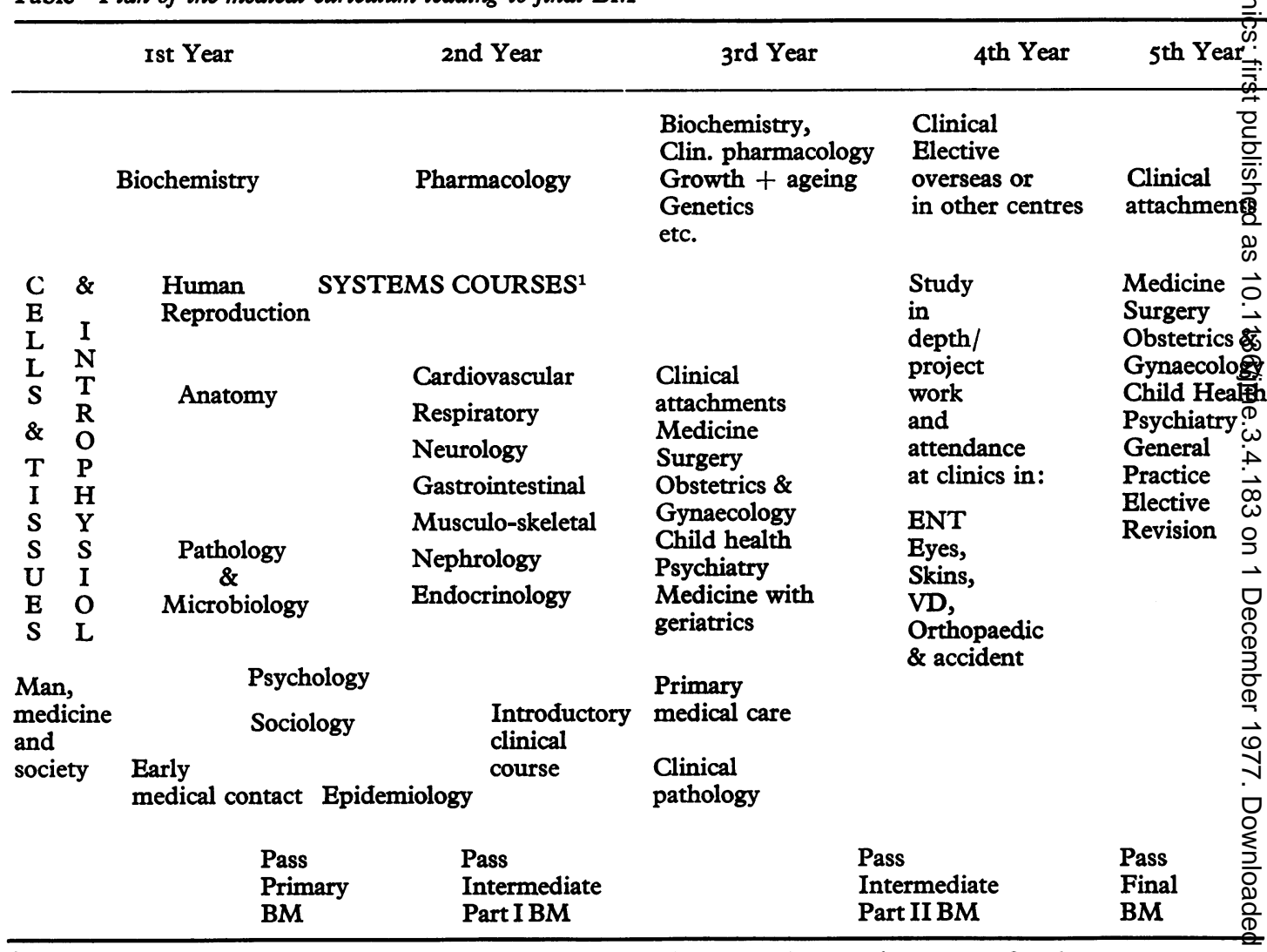

1The Systems Courses cover physiology, morphology, pathology and pharmacology, etc., of each system

Topics to be taught within other courses included the legal aspects of psychiatric practice and other problems of psychiatric assessment in relation to criminal law in the psychiatric course; the legal aspects in the care of handicapped children in the child health course; and the handling of drugs in relation to the Dangerous Drugs Acts and scheduled poisons would be taught in the pharmacology course. Other topics, such as the conflicts which might arise between teaching and patient care, the organization of medical care and problems relating to the multidisciplinary team should be taught in courses in the first and second year, namely, the 'Man, medicine and society' course and the sociology course in which they were already considered.

The working group also felt that there were many topics which could be dealt with better by meetings of student societies and that some multidisciplinary meetings with other societies, such as those held by the London Medical Group, would also help to stimulate discussion. Such topics included abortion, euthanasia, homosexuality and others which might become topical in the future.

In reaching these conclusions, the group considered the instruction given in II other medical schools which varied from none to an extensize course of 30 lectures.

As a result a paper was presented to the curyriculum subcommittee and the content of the course agreed. The first course was planned for May 1974 but had to be cancelled at the last minute owing to circumstances beyond everyones control. Nevertheless it was felt important that the first batch of medical students should receive this instruction and consequently some time was found in the fourth year and the first course was held 픔 January/February 1975.

\section{Course content and organization}

Initially seven sessions of approximately two $\$ \bar{D}$ two and a half hours were devoted to the course. These were divided between the theoretical aspects of legal medicine and the more philosophical aspects of medical ethics, three sessions being allocated to each and the seventh session beir used to hold a debate on an ethical topic such os 'The cancer patient has the right to be told tee truth'. Teaching methods used were lectures, films and seminars so that the course had the following shape. 
LEGAL MEDICINE

Three sessions included lectures and films dealing with problems of medical evidence in court, court procedure, forensic examination in criminal cases, the doctor and the police and the work of the coroner and his relationship to doctors.

\section{DEBATE}

One session is included.

\section{MEDICAL ETHICS}

Three sessions as seminars deal with the patient as an individual - consent - privacy; the definition of right and wrong - legal, medical and ethical views; and unethical medical research.

\section{Development}

The students' response to the initial course was favourable and the course was given a firm place in the fourth year. However, in such a position the student would already have had contact with patients and had to face problems which might be stressful. Consequently it was decided to arrange for one session of the introductory course in clinical methods to be devoted to ethical problems. This session is organized so that after an introductory talk the class is divided into discussion groups containing 20-30 students headed by a doctor, a nurse, a social worker and a fourth-year student. The hospital chaplain joins one group. This preliminary course seems popular and has taken place for the past two years. Indeed comment from participating fourth-year students who had no such introduction is that they wished they could have had it.

The main course in the fourth year has remained largely unaltered in content though the length has been reduced by one session, the debate being omitted. Teachers, however, have been varied in order to share the overall teaching load. They have and do include professors and lecturers from the Faculties of Law and Arts as well as Social Sciences and Medicine. Nurses, a senior policeman, general practitioners, solicitors and members of the general public have also been involved.

\section{Comment}

There is no doubt that the objectives of the original working group have been partly achieved and that the legal medicine and medical ethics course is appreciated by students. There is also no doubt that the Law and Arts faculties of the University have made a considerable contribution to this course and medical students have benefited greatly from their inclusion. The teaching methods used have proved satisfactory and the discussion in the seminars has been lively. However, in the courses taught to date numbers have not exceeded 80 students, and whether this form of teaching will be as successful with the total complement of 130 students time alone will tell. Other teaching methods such as 'role play' and 'mock trial' situations have been considered but have as yet proved too difficult to implement. Some topics not in the course have been dealt with by the medical society but the teaching envisaged in the preregistration year has not yet been achieved, though some local clinical tutors do run courses for their newly appointed preregistration staff. This aspect does, however, need more coordination and this, together with further modification and improvement in the existing course, remains a challenge.

\section{References}

Acheson, E D, University, medical school and community, British Medical fournal, 1970, 2, 683-687.

Acheson, E D, Southampton: the first years I, About Southampton Medical School, British Medical fournal, 1976, 2, 23-25.

Howell, J B L, Southampton: the first years: II, Systems courses, British Medical fournal, 1976, 2, 26-27.

Waters, W E, Marcer, D, and Topliss, E, Southampton: the first years III, Epidemiology, psychology and sociology, British Medical fournal, 1976, 2, 95-97.

Elstein, $M$, and Forbes, J A, Southampton: the first years IV, Early medical contact, British Medical fournal, 1976, 2, 97-98.

Forbes, J A, Southampton: the first years V, Primary medical care in Southampton, British Medical fournal, 1976, 2, 16I-162.

Normand, I C S, and Cantrell, E G, Southampton: the first years VI, The fourth year: study in depth,

British Medical fournal, 1976, 2, 162-163. 